\title{
Information Security and Learning Content Management System (LCMS)
}

\author{
Walid Qassim Qwaider \\ Department of Management Information Systems \\ Faculty of Science and Humanities in Ghat, PO BOX 445-11914 \\ Majmaah University, Saudi Arabia
}

\begin{abstract}
The learning environment has recently undergone a quantum leap due to rapid growth in information technology. This development has allowed the e-learning environment to take advantage of electronic tools to improve teaching methods using LCMS. The emergence of many e-learning institutions has accelerated the adoption of information and communication technology without taking due care and understanding of security concerns. LCMS is a new learning method that ultimately relies on the web in its implementation. This article argues essential elements of information security (IS) that require application through the information management system. On other hand, the paper also identifies anti IS measures that can boost IS within the information management system.
\end{abstract}

Keywords-E-Learning; LCMS; LMS; CMS; information security (IS)

\section{INTRODUCTION}

E-learning is a term that shows the utility of the IT to help boost the educational system between the teacher and the learner, also, electronic services that share similar characteristics, such as electric business, electronic government, and electronic health record. The behavior of the users of electronic services varies according to the nature of the roles and needs of electronic services. E-learning focuses users (teacher and student) on how to take advantage of e-learning for education and learning purposes [5]. Users of e-learning may require extended periods when doing e-learning compared to other electronic services.

E-learning depends on the use of electronic applications using the Internet and processes. It includes the application of e-learning system and learning tools via the Internet network and virtual classrooms. The e-learning content design over the Internet depends on the individual to acquire new knowledge and technological means to support the process of building education system [4].

LCMS based on the design, creation, and development of content or curriculum; it gives and supports authors, instructional designers, and materials specialists the ability to create, develop and modify learning content more efficiently. So that it is easy to control, collect, distribute and reuse them to suit the elements of the educational process: from the trainer, trainee, instructional designer and expert to the course [6].

The information security is the recent topic of interest and study with specialists all over the world. All educational institutions realize that the task of the value of information must be given to them and protect them from unauthorized individuals. Thus, information security is no longer marginalized, but a necessity in all educational institutions and corporations.

The work of information security specialists, many of the research in educational environments have not been focused on with great interest and especially IS applications in the LCMS environment [1]. Therefore, we must protect information because of the high sophistication of information that threatens the security of information technology.

Information security is very important in the LCMS because the main advantage that distinguishes between LCMS, LMS and CMS environments is the degree to which content management uses mail tools and gradual transfer to monitoring and trust in the educational system, and giving them access to the Internet to communicate between teacher and learner at any time and in any Place [2], so it requires educational institutions to take all steps and measures to ensure that all available information is correct and safe [3].

The initial part of this paper argues the status of LCMS definition, benefits, challenges and Information Threats on Internet, which are deemed securely in the content of education and defy in the application of LCMS.

In another part of this article consideration at IS in the LCMS. Issues such as legitimate new users (authorized), the reliability about the content of education, access to it, and there are also other things, all you need to protect information requirements in a request to preserve the prosperity of the LCMS process. Finally, the article discusses the possible essential elements of IS, which require application through the LCMS, as well as determine the anti-information that can enhance information security within the LCMS security.

\section{LITERATURE SURVEY}

\section{A. Learning Management Systems (LMS)}

LMS is a software program designed to help manage, track and evaluate training, learning, continuing education, and all learning activities in educational institutions. It is, therefore, a strategic solution for planning, description and managing all aspects of learning at the facility, including live broadcasts, virtual classes (distance learning) or instructor-directed courses, which will make educational activities that are separate and isolated from each other become fully integrated. On the other hand, LMS does not focus too much on content, 
neither regarding its composition nor reuse nor even regarding content development. [11].

LMS provides the infrastructure through which learning content has delivered and managed. It provides a set of software tools that perform a variety of tasks related to managing online learning and performance management. The LMS is an Internet-based software that performs the following functions: publishing, managing, defining paths and writing reports [7].

The interaction between the learner and the content includes registration of the student in the program, enrollment in the specific courses and activities, many entries into the online learning space such as virtual rooms and learning laboratories, tracking, participation and progress in performance, registration of marks. The interaction between the learner and the teacher includes communication, reception, and transmission of information: e-mail, instant messages, discussion, dialogue, virtual rooms and learning labs, the development of information related to the educational material such as a description of the course, On feedback from students and faculty [10].

\section{B. Content Management Systems (CMS)}

CMS system is a function used in small businesses, where there is a need to design contained within the system. It can be found on the CMS through forums and e-mail and chat [11].

CMS also works to support educational or academic courses. Where the instructor can set up a website and download the required documents in standard style such as Microsoft Word, PowerPoint, etc. when switching to web content. This requires some skills courses in this field, a standard the most suitable for trainers or teachers. It also supports the effectiveness of distance learning through virtual classrooms, where trainers to disseminate the core content that learners practice through the efficiency of the required learning method required, and then teachers to oversee the educational system. CMMS is a set of practical measures applied to identify appropriate teaching tools to interact with participants in educational institutions (teacher and learner) [10]. These rules aim to manage: access to data users, gather and share ideas and information, to help store data, select content, replication, and reporting preparation.

CMS represents news, discussion forum, file upload center, web directory, guestbook, management messaging, search engine email. A unique news system, specially programmed for the operation, is used. The program allows adding news in HTML style and can attach a picture to the report, display an image of the section that the story belongs to, or even add no image at all [12]. This is due to its overwhelming and CMS emphasis as a system based on e-learning component. Information courses on an ontological basis and discussion, such as, theses and scientific research, and many scenarios that we can use as a touch in e-learning.

\section{Learning Content Management System (LCMS)}

LCMS shows a multi-user environment for professionals, designers, and others in creating, configuring, processing, storing, retrieving, and using the management and delivery of digital educational content from the primary data repository [9].

LCMS is the upgraded generation of the LMS, but it increases the ability of many authors to participate in the creation, storage, use and reuse of learning content modules. The content management system can have considered as part of the Web-based learning structure. Therefore, when LCMS has called, it means a computer program that facilitates computer and Internet learning and has a branch within a broader family known as e-learning. At the same time, the LCMS is one of the types of Content Management System (CMS), which is, in turn, multiple applications that facilitate the design, testing, and dissemination of electronic content on the Internet [11]. Fig. 1 illustrates typical modular architecture components for the application. Implementation has divided into different parts: touch. Commonly used to identify application entities (ex, users, courses, resources, etc.); Operation - Used by requesting mail operations; Business Logic - is responsible for all actions that take place behind the scene. LCMS. Data class - Uses business logic of touch to extract and store data [20].

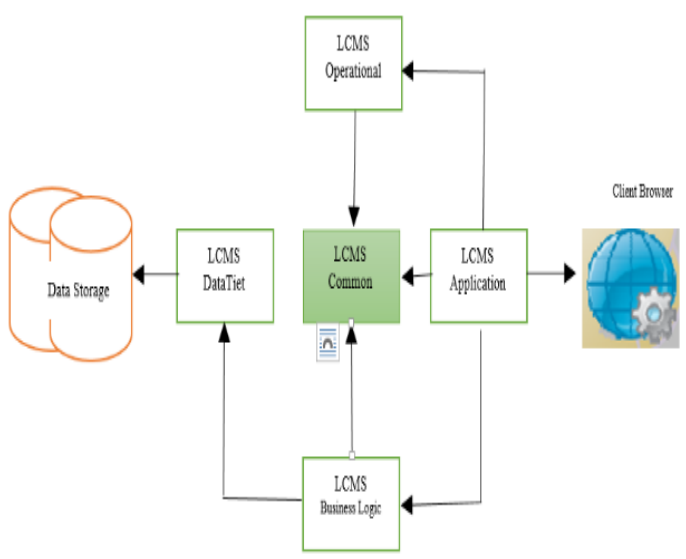

Fig. 1. LCMS's conceptual design.

\section{Features of LCMS, LMS, and CMS}

The three types of applications of educational institutions have a lot of capabilities and common characteristics. Table 1 provides a summary of the main advantages that educational institutions need to manage job content and learning, and to identify the range of functions they supply for CMS or LMS. It may be more or less per application for each group property. Such as you may have a dominant application feature (R) econtent, limited education (L), LCMS has an umbrella covering both LMS and CMS. Therefore, when LCMS is called, it means a computer program that facilitates computer and internet learning and has a branch within a broader family known as e-learning. At the same time, the LCMS has one of the types of CMS, which is, in turn, multiple applications that facilitate the design, testing, and dissemination of electronic content on the internet. Table 1 is a set of critical of Donatello's explorer and the Learners Hall to have an impact [13], [14], content presentation and efficiency, delivery evaluation, integration with other applications in the educational institution [15]. Content presentation, effectiveness, and delivery evaluation in the educational system, see Table 1. 
TABLE I. FEATURE OF CMS, LMS, AND LCMS [13], [14]

\begin{tabular}{|c|c|c|c|}
\hline \multicolumn{4}{|c|}{ Functionality (R: Robust, L: Limited) } \\
\hline \multirow[t]{2}{*}{ Features } & \multicolumn{3}{|c|}{ Functionality } \\
\hline & CMS & LMS & LCMS \\
\hline Educated management & & $R$ & L \\
\hline Content Management & $\mathrm{R}$ & & $\mathrm{R}$ \\
\hline Create content & L & & $R$ \\
\hline Manages sessions led by coach & & $\mathrm{R}$ & \\
\hline course catalog & & $R$ & $L$ \\
\hline Recording System & & $\mathrm{R}$ & L \\
\hline Talent management & & $R$ & L \\
\hline Launch and track e-learning & & $\mathrm{R}$ & L \\
\hline $\begin{array}{l}\text { The establishment of assessment } \\
\text { and evaluation, and Notes }\end{array}$ & & $\mathrm{R}$ & R \\
\hline $\begin{array}{l}\text { Library to search for executable } \\
\text { content for reuse }\end{array}$ & $\mathrm{R}$ & & $\mathrm{R}$ \\
\hline $\begin{array}{l}\text { Cooperation / asynchronous } \\
\text { learning tools }\end{array}$ & & L & $\mathrm{R}$ \\
\hline Integration with HR applications & & $\mathrm{R}$ & \\
\hline $\begin{array}{l}\text { Locate and Deliver Specific Content } \\
\text { to a Learner }\end{array}$ & $\mathrm{R}$ & & $\mathrm{R}$ \\
\hline
\end{tabular}

LCMS asserts management/authoring content and includes many attributes and advantages of a learning management system. It is a program used to control and smooth cooperating electronic meaning between the teacher and the learner's design. In recent years, LCMS has associated with learning management system [8]. Learning Systems Management provides an environment that enables the organization to plan the provision of content and the management of educational activities according to the service of the trainees. It also supports authoring systems and is easily integrated with CMS. The LMS has combined with LCMS by usual technical standards. LMS handles all content management tasks from storing content in the repository, assembling and decompiling material, engaging content within a traditional learning plan, and monitoring learners' performance during the course [7].

\section{LEARNING CONTENT MANAGEMENT SYSTEM BENEFITS}

LCMS systems include the design and development of elearning, especially in educational institutions, which include a large number of teachers and many educational topics and delivery [19]. There are many benefits of using LCMS are:

\section{A. LCMS regulated in one place}

Instead of e-learning content to be learned and benefit from the distributor on hard drives and different hardware engines, you can store all your courses e-learning in one place. LCMS reduces the risk of losing valuable information and easy to set up your e-learning path. Each member can be either a teacher or a learner access to information if you use a learning management system based on a cloud, as characterized by store information only on the remote server making the nature of the work of learning management systems compatible with the standard online collaboration between teacher and learner.

\section{B. Provides unlimited access to e-learning materials}

Once downloaded courses private e-learning on your LMS and dissemination, and learners have the right to unlimited access to the information they need. The main reason is why the LCMS is essential for global audiences in different time zones.

\section{Easily advance learner performance tracks}

The benefits of LCMS give you the ability to track the progress of the learner and to make sure their performance. For example, if a learner on the Internet is not able to complete the e-learning scenario successfully, you can help them provide extra resources to improve their performance.

\section{Reduces the education and development costs}

LCMS allows reduced coach travel costs and rental training site over the Internet, and the decisions of the e-learning printed.

\section{E. Reduces the learning and development time}

LCMS can reduce training and education Times online, by giving learners only online information they need directly and orderly. Instead of having to sit through a training course online prolonged for half an hour or more.

\section{F. Organizations keep up to date with compliance systems}

Must comply with the dates of the institution to which he belongs and with the current compliance systems, where learning invaluable management tool. However, using the learning management system in educational institutions gives you the ability to add compliance with the new standards for an informative course on the Internet in a matter of minutes.

\section{G. Quickly and easily expands e-learning courses}

If you want to add additional courses online course for your e-learning, you can only access the learning management system and make adjustments required without re-repeating the course of learning the entire mail.

\section{H. Integrated social learning experiences}

The benefits of LCMS are that it facilitates the integration of social learning in e-learning strategy. Since LMS is already, you can include links to pages Facebook, Twitter and LinkedIn groups, and educational forums on the Internet that could be helpful to students and learners.

\section{Challenges IN THE LCMS}

Participants in the touch system must ensure that they have the various tools, equipment, and software necessary in the LCMS application. Technical levels vary between teachers and learners, as the low level of professional participation of participants represents a significant challenge to the content of education. This requires addressing the problem through the work of workshops and training courses commensurate with each level of trainees.

The application of LCMS in educational institutions is a qualitative leap in the education process for both teachers and learners. The educational system sends professional staff to specialized training centers accredited by the educational agency and are off-site where the sculpture is clear from the time and place of learning. The successful use of the LCMS program requires that all participants be encouraged to apply for the program with helping rewards and incentives. LCMS needs active and successful support from managers and supervisors throughout the institution. 
To activate the effectiveness of online learning learners need to be committed to applying for the LCMS program without interruption, which leads to difficulty in a confrontation in retrieving and practicing the application again, as it takes time to identify the latest apps and updated developments on LCMS and this can be challenging.

The LCMS approach requires that it depend on the design of the learning content, rather than relying solely on the delivery of the instructional material. Teachers must recognize the strategic development of education, and more use that is significant and development of educational content is essential. All participants should follow up and train all participants on how to use the LCMS program and develop their skills [16].

\section{INFORMATION SECURITY AND THREATS}

\section{A. Information Security}

The term information security, the first thing that comes to mind is the need to maintain the confidentiality and protection of information from intrusions and threats from other companies that may threaten the security of data. The most important obstacles facing the application of e-businesses and the fear of penetration and the information system and the following Privacy Information and beneficiaries loss. Information security in information system as an aspect of information security and the integrity of confidential information and ensure its survival, non-deletion or destruction [3].

The fact is that maintaining the confidentiality and protection of information is just one of the aspects of security; where specialists believed that the computer information security consists of the same degree of importance of three elements. These components are:

\section{1) Data confidentiality}

This aspect includes all the necessary measures to prevent unauthorized information confidential, and examples of the information that is keen to privacy: personal information, education and information on a particular educational institution, the financial situation of the organization, and military intelligence.

\section{2) Data Integrity}

Does not concern us in this aspect to maintain the confidentiality of information, but what concerns us is to take the necessary steps to protect the knowledge of the change measures, and there are many examples of this demand has been hand publish the lists of accepted names which have applied to work with, it is likely someone deletes some of the names, and the inclusion of names instead, causing a lot of confusion and embarrassment to the party concerned.

\section{3) Availability}

Maintaining the confidentiality of information integrity is essential, no doubt, but this information become worthless if it is entitled to see it cannot have reached, or that access to it needs to be for a long time, and take the attackers various means to deprive the beneficiaries of the access to information, one of these methods to delete the same information, or to attack the devices that store information about where and paralyzed the work, shows Fig. 2. [18].

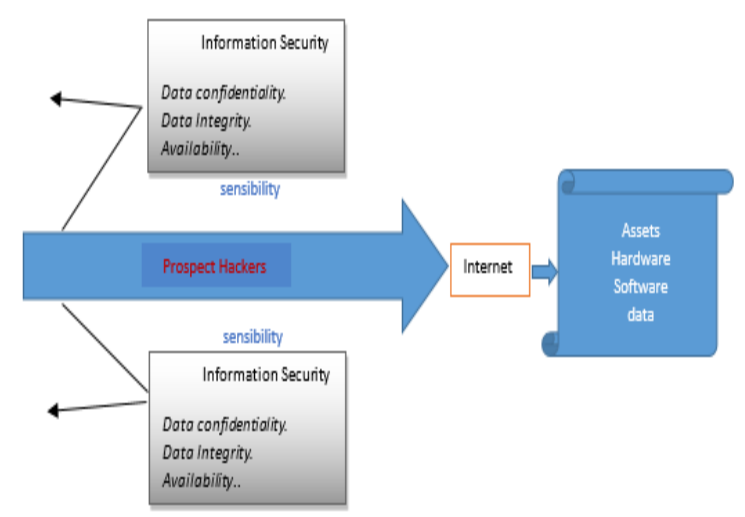

Fig. 2. Elements of information security.

\section{B. Information Threats on the Internet}

In light of the information and communication technology, individuals and institutions of all kinds and to get the many benefits of this information is to get them quickly and accurately. There are many methods followed by educational systems to protect the network from threats, including programs and equipment, including information and data, and there are methods of protection of data carried out locally through the cloud which contains the applications of security on the site of network equipment or by remote communication [17]. The following are the most prominent threats that may have exposed to information, which are as follows:

1) Intentional and intentional software attacks

(Viruses, thread, macros, and refusal of service), and technology used, software, failure of errors (bugs, coding problems, gaps unknown).

\section{2) Intentional fault or human failure or unintentional} (Accidents, employee errors).

3) Deliberate LMS tracts of spying or overrun.

(Non-authorized) (Unauthorized incoming or data) Gathering.

4) The statute of deliberate vandalism, and Failure of hardware or artistic mistake, and business intentional information theft.

5) Settlement of ideological ownership: (piracy and intellectual rights of authors and abuse).

6) The quality of the distractions provided by the service providers: (electricity and service issues WAN).

7) Use old technology, and deliberate extortion business information: (blackmail for disclosure of data).

\section{INFORMATION SECURITY AND IMPLEMENTATION OF LCMS}

Information security as a science that works to protect information from the threats that threaten it or the barrier that prevents it from being attacked by providing the necessary tools and means to protect it from internal or external risks. To 
keep the educational process going high. Also, there is a good return on investment and employment. The objectives of the Learning Management System are to provide education and a learning management system for all. Ensuring the availability and integrity of information is the primary objective of any organization about information security and protection against external threats. LCMS aims to provide the required safety information to users without any outgoing risks [3]. Implementation of the information system in the information management system is to ensure access to the touch environment by authorized users when needed. Also, lack of access to information has a significant impact on users of elearning services and e-learning providers. Some features affect touch is privacy and security for international mail delivery and collaborative education [17], and data against potential security incidents. These anti-information security measures are:

\section{A. Authentication}

The process by which the identity and user data are verified and verified by the teacher or learner before giving them access to system resources, depending on the access controls used such as passwords.

\section{B. Authorize}

The process in which the information to have accessed, the operations to have performed or the services to have used are permitted only by the rights and authorizations granted to the user. As such as anti-security information needs to obtain an access control license.

\section{Confidentiality}

Ensure that information is handled only by authorized parties.

\section{Safety}

It means keeping data from modification or modifying it from people who are not authorized to access it. When someone intentionally or unintentionally changes, deletes, or violates the integrity or harm of essential data files, which is not permitted, this is a violation of the integrity of the data.

\section{E. Availability}

Ensure that information systems remain available and that the necessary data is available or can be retrieved for use when needed.

\section{$F$. The accuracy of information}

The accuracy of the information indicates that the error-free and valuable information provided by the user to hold at the request of the user who expects.

\section{G. Useful information It is worth mentioning.}

That the aim of this information to be useful Information in the form of a readable does not make sense, and therefore not fit for a particular purpose.

\section{H. Possession of information}

Referred to the quality, the presence, or the right of ownership or control of information and acquisition requirement, Fig. 3 shows an application IS for LCMS. In preparing a model for LCMS for the student, the information required by users has provided via the Internet.

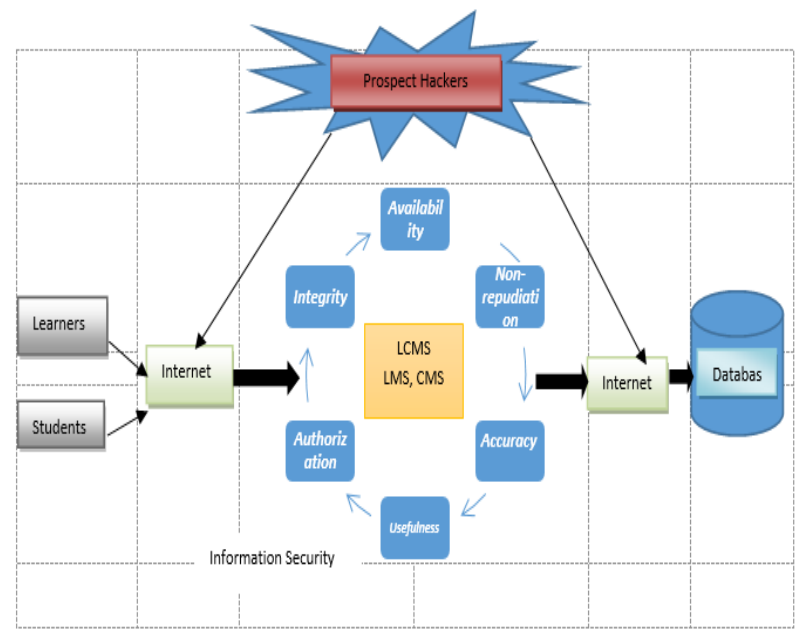

Fig. 3. Application IS for LCMS.

Information security records specific events, such as e-mail access (in an e-mail server), or the process of verifying passwords that occur in the system - whether a computer, network or database - and automatically for the ability to audit through tracing. The situations in which these systems pass, in addition to the process of reviewing the work and externally

\section{FRAMEWORK}

E-learning environment requires LCMS framework that can serve as evidence to support supplier in a concept of IS management in the learning content management system. LCMS scope must be seen in the context of LCMS to contain all elements of the appropriate characteristics necessary when the general framework for education-mail mode, it is required to identify threats and attacks in e-learning and work on them to include the prosperity of frames LCMS. The context should consist of e-learning various detailed information on the policies and the ensure process and procedures and organizational structures in the LCMS environment, and to identify the functions of software and hardware to promote the implementation of the security and confidentiality of the information. Also considered is requiring maintenance required procedures and amendments.

\section{CONCLUSION AND FUTURE WORK}

Learning Content Management System faces many challenges as we mentioned earlier in the implementation of tools and programs, notably the problem of security and safety information. Security elements, such as the data confidentiality, Data Integrity, and availability of training courses and data in space and time, these factors help to build LCMS setting safe and reserved. Furthermore, the learners advantage from the existence of an active and reliable LCMS setting, and they can take advantage of the growing e-learning, and be a good and profitable investment in entrepreneurship.

LCMS was grown and evolved very fast. Benefits provided by increasing the number of beneficiaries of e-learning. Still, function LCMS expansion relies difficult on the network. 
Another hand, as the web has become a space for forbidden action, they are placed under the LCMS threats to nonmembers and groups and outlaws unauthorized and illegitimate. The Security elements, such as the data confidentiality, Data Integrity, and availability of the information and materials in LCMS setting demand that there be a set of features and attributes anti, such as IT security appliances and software, and must have implemented. However, it has considered a way inadequate. Moreover, the group of international solidarity standards and the security of IT applied to support the best in the successful implementation of IS in the LCMS setting.

The future work on this topic is to develop the LCMS Information Security Introduction Model further. The trial will be the next focus on the application in the real world situation. It will also focus on benchmarking and cloud computing comparisons for other web services. This proposed form has many benefits that can solve many problems related to the LCMS environment successfully.

\section{ACKNOWLEDGMENT}

The author would like to thank Deanship of Scientific Research at Majmaah University for supporting this work under Project Number No. 37/104.

\section{REFERENCES}

[1] Kritzinger .E. (2006). Information security in an e-learning environment, school of computing, University of South Africa, PO Box 392, UNISA, 003.

[2] Alwi. N. H.M., Fan I.Shing. (2010). e-learning and information security management, The international journal of the digital society, volume 1 , Issue 2.

[3] Kritzinger .E., Solms. S.H von. (2006). e-learning: incorporating information security (IS) governance, Issues in IS and IT, volume 3.

[4] Mihalca.R., Uta. A. (2008). Knowledge management in an e-learning system. Revisit informatics economicănr.2(46).
[5] Hayaati.N., Alwi .M., Ip-Shing Fan. (2010). E-Learning and information security management. International Journal of Digital Society, volume 1, Issue 2.

[6] Jurubescul.T. (2008). Learning content management systems (LCMS). Revista Informatica economic, no. 4 (48).

[7] Sejzi .A. A., Arisa .B. (2013). Learning Management System LMS and LCMS at the virtual university. Another international seminar on quality assurance and educational institution.

[8] Renaux, E., Caron, P. and Le Pallec, X. (2005). Learning Management System Ingredient -basic design: a model-driven approach, nice team, trigone laboratory, University of Lille, France, match, conference submission paper no 26.

[9] Irlbeck, S., Mowat, J. (2005). Learning content management system (LCMS), Capella University.

[10] Ninomiya. S., Chawan. M., Meshram B.B. (2011). CMS, LMS, and LCMS For eLearning. International Journal of Computer Science Issues (IJCSI). Vol. 8, Issue 2, ISSN (Online): 1694-0814.

[11] Grenache. H.C., Radigales F. G. Communication software laboratory academic year 2007-2008. E-learning platforms, moodle and dokeos. Group 95.

[12] Dietmar. R., Mario A. (2006). Michael Piotrowski education components: A component-based e-learning environment ACM 978-159593-610.

[13] Donello J. (2004). Theory and practice: LCMS. Retrieved February 25.

[14] Hall, B. (2003). LMS and LCMS demystified.

[15] Sonja, I, Joanne M. (2006). Learning Content Management System (LCMS). Capella University.

[16] Staley. L. (2007). Blended learning guide, Spanish language outreach program coordinator, web Junction.

[17] Najwa, A., Ip-Shing, F. (2010). E-learning and IS management. International Journal of digital society, volume 1, Issue 2.

[18] Goss, Gavin. (2009). Enabling e-Learning 2.0 in IS education: A semantic web approach, Nelson Mandela metropolitan university.

[19] Pappas. C. (2016).The Top 8 benefits of using LMS, e-learning industry, LMS.

[20] Bexheti L. A. (2008). Development of LCMS. International journal of systems Application and development, Issue 1, volume 2. 